\title{
WAVED SPHINX AT THE PAS, MANITOBA
}

WALTER KRIVDA, Box 864, The Pas, Manitoba. R9A 1 K8

During 30 years of collecting insects in The Pas area, I have only twice previously seen this large grey hawk moth, the Waved Sphinx (Ceratomia undulosa), hovering over late blooming lilacs after sunset, and failed to net it both times! Ash is one of the main food plants of this moth, therefore it should occur here as ash trees grow wild in this area along the river at Rhalls Island and also in quantity in the valley west of town. The area is likely on the northern edge of this hawk moth's range in the prairie provinces. It was therefore a marvelous experience to find a perfect specimen sitting on a brick wall of the Margaret Barbour Collegiate on 31 July 1982.

Mercury vapour lights at the ten foot level on the outside walls of the school draw insects in great numbers to sit on the bricks. They are easily collected into insect killing bottles. One can be very selective in collecting, as thousands of insects of many orders congregate at the lights.

This summer another locally taken Waved Sphinx was seen in a student's collection. This moth came from the valley west of The Pas, bordering on The Pas river.

The Waved Sphinx Moth is more frequent in Southern Manitoba. On 6 July 1962 many were seen at the north gate of Riding Mountain National Park just south of Dauphin, Manitoba. Franklin and Paul Chermock (veteran collectors and writers on American insects) and I saw dozens circling the flood lights at the gate. Paul collected several specimens that are now in the Allyn Museum of Entomology at Sarasota, Florida. (The entire Chermock collection

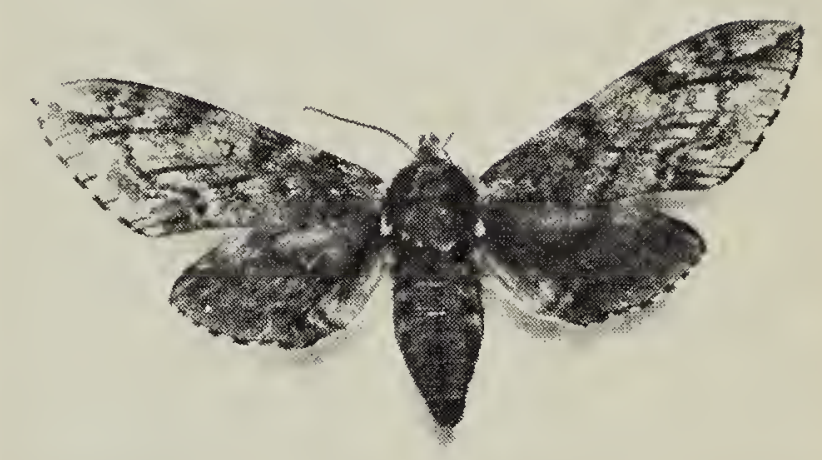

Waved Sphinx; The Pas, Manitoba; 31 July 1982; W. Krivda: W. Keetok. Terry Dartnell

has been moved there from Baltimore, Maryland.)

I have found the best place to collect hawk moths in this area, is at Lilac trees just after sunset. They fly in the early part of the evening, till perhaps 10:00 p.m. in any number and seem to drop off after that time. This may be due to temperature changes or simply that they have had their fill of nectar and are no longer feeding.

The different hawk moth species vary in number here from year to year. Some that were frequent in the 1950's and 60's are now scarce; the Black Apple Sphinx (Sphinx gordius borealis), and that magnificent giant the Big Poplar Sphinx (Pachysphinx modesta borealis) are two cases in point. These may well vary numerically in cycles of greater or lesser duration. Collecting over many years can help to elucidate some of these cycles. Other hawk moths, like the Clemens Hawkmoth (Sphinx luscitosa), seem to always be rare and are not seen for years at a time. These may also be on the edge of their geographic range here and survive in favourable years only to disappear again. 